\title{
Association of neutrophil to lymphocyte ratio with different glucose metabolism status
}

\author{
Betül Ekiz Bilir ${ }^{1}$, Neslihan Soysal Atile ${ }^{1}$, Bülent Bilir ${ }^{2}$, Birol TOPÇU ${ }^{3}$, Sonat Pınar KARA², Derya BAYKIZ ${ }^{4}$, Murat Aydın ${ }^{5}$ \\ ${ }^{1}$ Tekirdağ State Hospital, Endocrinology and Metabolic Diseases Department, Tekirdağ, Turkey \\ ${ }^{2}$ Namık Kemal University, Medical Faculty, Internal Medicine Department, Tekirdağ, Turkey \\ ${ }^{3}$ Namık Kemal University, Medical Faculty, Biostatistics Department, Tekirdağ, Turkey \\ ${ }^{4}$ Tekirdağ State Hospital, Cardiology Department, Tekirdağ, Turkey \\ ${ }^{5}$ Namık Kemal University, Medical Faculty, Biochemistry Department, Tekirdağ, Turkey
}

\section{INTRODUCTION}

Several studies have shown that prediabetic patients had increased concentrations of inflammatory markers and this association is independent of underlying obesity. Neutrophil to lymphocyte ratio (NLR) is considered as a new inflammatory marker and has been studied extensively in a variety of clinical conditions especially in solid tumors and cardiovascular diseases. Studies evaluating the subclinical inflammation in prediabetes revealed positive association of some inflammatory markers with hyperglycemia ${ }^{(1,2)}$. The aim of this study is to evaluate the association of NLR with different glucose metabolism status groups.

\section{METHODS \& DESIGN}

The study included 259 patients (213 female, 46 male; mean ages $47,4 \pm 11,5$ and $48,8 \pm 15,7$ respectively) who admitted to an out-patient endocrinology clinic of a state hospital in Turkey. The asymptomatic adults were classified in 3 groups as normal glucose metabolism, impaired fasting glucose and impaired glucose tolerance groups according to 75 gr-oral glucose tolerance test. The patients who had diabetes, any thyroid dysfunction, malignancy, pregnancy, any acute or chronic infectious or inflammatory disease or patients who were on oral anti-diabetic drugs were excluded from the study.

\begin{tabular}{|c|c|c|c|c|c|c|c|c|c|}
\hline Groups & Age & BMI & Glucose & Insulin & HOMA-IR & TG & HDL & LDL & NLR \\
\hline $\begin{array}{c}\text { Normal } \\
(n=53)\end{array}$ & $42.2 \pm 13,9$ & $34,7 \pm 7,1$ & $93,9 \pm 7,3$ & $11,6 \pm 6,9$ & $2,7 \pm 1,6$ & $152 \pm 97$ & $48 \pm 14$ & $136 \pm 31$ & $1,86 \pm 0,67$ \\
\hline $\begin{array}{c}\text { IFG } \\
(n=120)\end{array}$ & $48,7 \pm 11,1$ & $34,6 \pm 7$ & $106,8 \pm 7$ & $12,9 \pm 6,5$ & $3,4 \pm 1,7$ & $160 \pm 90$ & $44 \pm 13$ & $138 \pm 39$ & $1,8 \pm 0,61$ \\
\hline $\begin{array}{c}\text { IGT } \\
(\mathrm{n}=86)\end{array}$ & $49,5 \pm 12,3$ & $35,9 \pm 8$ & $107,6 \pm 8,1$ & $13,7 \pm 7,3$ & $3,7 \pm 2,1$ & $178 \pm 106$ & $45 \pm 12$ & $133 \pm 36$ & $1,85 \pm 0,76$ \\
\hline $\mathrm{p}$ value & 0,001 & 0,514 & 0,000 & 0,365 & 0,047 & 0,255 & 0,212 & 0,646 & 0,501 \\
\hline
\end{tabular}

Body mass indices of patients, serum fasting glucose and insulin levels, lipid parameters and complete blood counts with differentials were registered. In statistical analysis, SPSS-17 version was used.

\section{RESULTS}

The exact results are shown in the table. There were statistically significant differences between groups in terms of fasting glucose and HOMA-IR levels as expected ( $p=0,000$ and $p=0,047$ respectively). These differences were due to the difference between normal and prediabetic group but no difference was found between IFG and IGT groups. Otherwise there are no differences in terms of BMI, insulin, lipids and NLR.

\section{CONCLUSION}

Glucose metabolism status was not associated with NLR in our small study cohort. Studies based on a wider population might give a different result in this manner.

\section{REFERENCES}

(1) Post load hyperglycemia is associated with increased subclinical inflammation in patients with prediabetes. Colak A, Akinci B, Diniz G, Turkon H, Ergonen F, Yalcin H, Coker I. Scand J Clin Lab Invest. 2013 Aug;73(5):422-7.

(2) Fiorentino TV, Hribal ML, Perticone M, Andreozzi F, Sciacqua A, Perticone F, Sesti G. Unfavorable inflammatory profile in adults at risk of type 2 diabetes identified by hemoglobin Alc levels according to the American Diabetes Association criteria. Acta Diabetol. 2015 Apr;52(2):349-56. 